REVISTA CATALANA DE DRET AMBIENTAL Vol. V Núm. 2 (2014): 1 - 11

-Crònica-

\title{
DERECHO Y POLÍTICAS AMBIENTALES EN CASTILLA Y LEÓN
}

\author{
ÍÑIGo SANZ RUBIALES \\ Catedrático de Derecho Administrativo (acreditado) \\ Universidad de Valladolid
}


Sumario. 1. Introducción. 2. Una reforma en profundidad de la Ley de Prevención Ambiental. 3. La incidencia ambiental de otras leyes sectoriales. 3.1. La nueva Ley de Industria. 3.2. La reforma de la legislación urbanística. 3.3. La ley de reforma de la Administración pública. 4. Una pequeña modificación de las comisiones territoriales de Medio Ambiente y Urbanismo. 5. Un proyecto de interés regional para el tratamiento de residuos industriales. 6. Una ley que deja de serlo: la inconstitucionalidad de la Ley de convalidación del proyecto Meseta-Sky.

\section{Introducción}

En este semestre hay que destacar la aprobación de la modificación de la Ley de Prevención Ambiental; se trata de una reforma de calado que entra de lleno en la disciplina ambiental (calidad ambiental). Otras leyes sectoriales inciden parcialmente en el medio ambiente y por eso se traen a colación. Desde el punto de vista de la organización administrativa, hay que reseñar únicamente una modificación puntual de las comisiones territoriales de Medio Ambiente y de Urbanismo. Y se alude, a título de "legislación negativa", a la reciente sentencia del Tribunal Constitucional que anula la ley singular de aprobación del proyecto de Meseta-Sky, la tercera en poco más de un año que declara inconstitucionales proyectos regionales aprobados por ley.

\section{Una reforma en profundidad de la Ley de Prevención Ambiental}

La gran novedad legislativa estrictamente medioambiental ha sido la modificación de la Ley 11/2003, de 8 de abril, de Prevención Ambiental, que regula diversos regímenes de protección preventiva del ambiente (evaluación de impacto, autorización ambiental integrada, licencia ambiental y comunicación previa). La nueva Ley 8/2014, de 8 de octubre, busca racionalizar la regulación preventiva simplificando la aplicación de las diversas técnicas y evitando contradicciones o reiteraciones.

Los motivos que han llevado al legislador a acometer esta profunda reforma son conocidos: por una parte, la conveniencia de simplificar trámites y de no disuadir, con exigencias burocráticas desproporcionadas, la creación de nuevas actividades comerciales o industriales en la coyuntura actual de crisis económica; por otra, continuar con la progresiva sustitución (donde haya lugar a ello) de procedimientos de control previo por procedimientos de control durante el funcionamiento de la actividad. Estos aspectos exigen una especial ponderación de las reformas para evitar que la mayor agilidad burocrática no implique un efecto negativo sobre el interés general medioambiental, como tendremos ocasión de valorar. Igualmente, la nueva Ley viene 
justificada por la necesidad de adaptar la normativa autonómica a la nueva Ley básica estatal 21/2013, de 9 de diciembre, de Evaluación Ambiental, que regula la evaluación de proyectos y de planes, y a la reguladora de la autorización ambiental integrada en la nueva Ley 5/2013, que transpone la Directiva 2010/75, sobre emisiones industriales (que a su vez derogó la inicial Directiva 96/61).

En cuanto al ámbito de aplicación, la Ley 8/2014 amplía los supuestos excluidos de su regulación normativa; ahora bien, esta exclusión no implica, aunque pudiera parecerlo prima facie, una reducción del control preventivo, sino que viene a evitar reiteraciones en el proceso controlador. En efecto, como señala la exposición de motivos, se excluyen diversos supuestos por exigencia de la normativa básica estatal o bien porque ya están regulados en la normativa sectorial aplicable (actividades contaminantes en materia de defensa o referidas a la actividad laboral en los lugares de trabajo, actividades e instalaciones vinculadas a la investigación y experimentación de nuevos productos o a la energía nuclear).

Igualmente, la Ley acomete las diferencias entre los conceptos de modificación sustancial y no sustancial de la autorización ambiental (art. 6 bis), cuya indeterminación había venido generando numerosos conflictos interpretativos, como pone de manifiesto el abultado número de decisiones judiciales recaídas en relación con este tema, también en los tribunales de la región. El criterio diferenciador se aplica también, igualmente, a las licencias y a las comunicaciones ambientales, para ensanchar el ámbito de la seguridad jurídica en la aplicación de estas técnicas.

En esta línea de buscar la agilización de los procedimientos, el nuevo artículo 11.2 de la Ley, introducido ahora, rompe con el criterio absoluto y tradicional de que la autorización ambiental debe ser previa a la urbanística. En efecto, solo se exige este orden de precedencia "cuando la actividad prevista pretenda ubicarse en suelo rústico". Según la exposición de motivos: "Este cambio deriva de que en numerosas ocasiones las actividades autorizadas por este régimen de intervención pueden desarrollarse en edificaciones situadas en polígonos industriales, de uso general y no específico, lo que además conlleva una disminución sustancial en tiempo para la implantación de las actividades".

En cuanto al ámbito de aplicación de la licencia ambiental, la Ley amplía razonablemente su espectro (art. 24.1). Mantiene, por una parte, la cláusula residual (se someten a licencia las actividades no sometidas a autorización — por arriba - ni 
comunicación previa — por abajo-), pero, por otra, añade una cláusula en virtud de la cual se someten también a licencia las actividades sometidas a evaluación de impacto ambiental simplificada (lo que en ocasiones se ha dado en llamar preevaluación o evaluación prima facie) y que, de acuerdo con esta evaluación simplificada, no precisan someterse a la ordinaria posteriormente. De esta forma, se sobreentiende que dichas actividades no tienen un impacto ambiental relevante, aunque tampoco insignificante..., lo que parece cuadrar bastante con la finalidad de la determinación residual de las actividades sometidas a licencia. Este planteamiento, además, responde al intento de evitar controles innecesarios. Como recuerda la exposición de motivos, los proyectos sometidos a evaluación de impacto ordinaria cuyo resultado haya sido favorable solamente deberán someterse a comunicación previa (exigible a efectos meramente informativos) puesto que el control ambiental sensu stricto ya viene realizado por la propia autorización. Se eluden también los solapamientos de varios controles mediante el ajuste de la actuación de las comisiones territoriales de Medio Ambiente y Urbanismo. Estos órganos colegiados tenían que intervenir obligatoriamente en el procedimiento de emisión de licencias ambientales (cuyo otorgamiento correspondía al alcalde). Tras la reforma, se exime de este trámite con carácter general porque "la Administración de la Comunidad Autónoma controla ya las actividades o instalaciones sujetas a este régimen a través de otros medios de intervención administrativa basados en la normativa en materia de residuos y de emisiones a la atmósfera, lo que hace innecesario el trámite suprimido" (EM). De esta forma, el régimen de las licencias ambientales se "remunicipaliza" en un cierto sentido al pasar a referirse a aspectos de competencia básicamente municipal, habida cuenta de que los demás aspectos ambientales de la actividad autorizada son controlados por la Administración autonómica a través de otras vías.

La Ley prevé la posibilidad de modificar de oficio la licencia por diversas causas (art. 41). Estamos ante una modificación derivada de un cambio de circunstancias físicas o legales. No tiene carácter sancionador. La Ley, desafortunadamente, la califica como "revisión de oficio", pero su naturaleza está más próxima a la revocación (parcial) en la línea del viejo artículo 16 del Reglamento de Servicios de las Corporaciones Locales, porque no se refiere a vicios de nulidad radical, de pleno derecho, existentes ab initio, sino a la acomodación de la licencia a las nuevas circunstancias. 
En cuanto a la comunicación ambiental, la Ley amplía el listado de actividades de escasa incidencia ambiental sometidas a este régimen, pero también se incluyen otras actividades o instalaciones con incidencia ambiental más significativa que, por normas ambientales sectoriales, han de ser supervisadas en procedimientos administrativos específicos por la Administración regional.

Desde esta perspectiva de la simplificación, estas reformas son razonables y el único "pero" es que deberían haberse plasmado mucho tiempo antes. Pero nunca es tarde si la dicha es buena.

En cuanto a la evaluación de impacto ambiental, la reforma incide - como se ha señalado más arriba - en el ajuste de la normativa autonómica a la nueva Ley estatal. El régimen que se deroga con esta ley se basaba en dos tipos de evaluaciones de impacto de proyectos por razón de su incidencia ambiental, de su diferente procedimiento y del órgano ambiental competente (central o periférico) para resolver. Ahora la Ley se ajusta al binomio preevaluación o evaluación simplificada y evaluación ordinaria, que no son alternativas como antes porque la primera puede exigir que el proyecto se someta (o no) a la segunda. De acuerdo con ello, se suprime el anexo IV (relativo a la evaluación por órgano periférico) y se adopta una remisión en bloque a los supuestos de la Ley estatal, sin perjuicio de incluir (únicamente) cuatro tipos de proyectos específicamente autonómicos sometidos a la evaluación ordinaria por motivos justificados, "bien porque se consideran demasiado altos los umbrales establecidos en la normativa básica estatal, en el caso de los dos tipos de industria energética, bien porque se propone la decisión sobre sometimiento en fase anterior a lo establecido en dicha normativa básica, en los polígonos industriales, bien por ser proyectos no contemplados en ella, como las industrias productoras de residuos peligrosos, parece oportuno que se sometan a evaluación de impacto ambiental simplificada, además de los establecidos en la normativa básica estatal” (EM). El tiempo dirá si la ausencia de otros proyectos autonómicos puede ir en detrimento de la protección del ambiente regional.

En definitiva, estamos ante una reforma razonable que tiene en cuenta la experiencia acumulada y que busca — tiempo habrá para comprobar si lo consigue — simplificar los trámites administrativos sin reducir la tutela ambiental.

\section{La incidencia ambiental de otras leyes sectoriales}




\subsection{La nueva Ley de Industria}

La Ley 6/2014, de 12 de septiembre, de Industria de Castilla y León, no es una norma propiamente ambiental. No se puede olvidar, sin embargo, que la actividad industrial constituye una fuente importantísima de contaminación (actualmente solo superada por la actividad agropecuaria intensiva).

Esta ley constituye una novedosa manera de mirar la industria, hasta el momento no suficientemente considerada. Y, en lo que se refiere al medio ambiente, esa mirada se plasma en la regulación de la seguridad industrial. El artículo 4 incluye entre los fines de la Ley: "b) El establecimiento de un marco de seguridad industrial para las personas, los bienes y el medio ambiente". Y el artículo 2.3 anuncia ya la perspectiva de análisis de la seguridad industrial: "Las disposiciones sobre seguridad industrial serán de aplicación en todo caso a las instalaciones, equipos, actividades, procesos y productos industriales que, radicados en el territorio de la Comunidad de Castilla y León, utilicen o incorporen elementos, mecanismos o técnicas susceptibles [sic] de producir daños o perjuicios a las personas, flora, fauna, bienes o al medio ambiente" (véase, igualmente, el artículo 5.2).

Junto a los daños al medio ambiente, aparecen los riesgos. El artículo 5.3 reconoce la obligación administrativa en materia de riesgos industriales: "A estos efectos se procurará limitar las causas que originan los riesgos, así como establecer los controles para detectarlos y mitigar las consecuencias de posibles accidentes”. Y se consideran riesgos relacionados con la seguridad industrial "los que puedan producir daños a personas, flora, fauna, bienes o medio ambiente $\mathrm{y}$, en particular, los incendios, las explosiones y otros hechos susceptibles de producir quemaduras, intoxicaciones, envenenamiento o asfixia, electrocución, contaminación física, química o biológica, así como cualquier otro que pudiera preverse en la normativa aplicable sobre seguridad".

El medio ambiente, de esta forma, permite superar el concepto de seguridad industrial limitado a la directa protección de las personas. Ahora bien, la Ley no contiene una regulación específica de esta materia porque ya está acogida en la legislación sectorial. De ahí que el artículo 6.6 se remita a ella: "La intervención administrativa de control frente a los riesgos relacionados con el medio ambiente se regirá por la normativa específica aplicable en cada caso". Sin perjuicio de ello, la Ley regula los controles administrativos (art. 14), la inspección (art. 20) y las medidas provisionales (art. 23) en esta materia con el objetivo — entre otros— de la protección ambiental. 


\subsection{La reforma de la legislación urbanística}

La Ley 7/2014, de 12 de septiembre, de medidas sobre rehabilitación, regeneración y renovación urbana, y sobre sostenibilidad, coordinación y simplificación en materia de urbanismo, desarrolla en el ámbito territorial de Castilla y León la Ley estatal 8/2013, de 26 de junio, de rehabilitación, regeneración y renovación urbanas, para integrar los aspectos ambientales, económicos y sociales en el urbanismo "con el objetivo de rehabilitar el patrimonio edificado, revitalizar el tejido social, mejorar la eficiencia ecológica de la ciudad y promover formas de transporte sostenibles, a través de la coordinación administrativa como herramienta de gestión" (EM).

"En pocos años, el concepto de sostenibilidad se ha instalado en el centro del debate urbanístico, y es hoy un elemento imprescindible en los procesos de planificación". De ahí la importancia que la Ley concede al denominado "crecimiento compacto" y que supone una importante modificación de la Ley 5/1999, de 8 de abril, de Urbanismo. Pero, además de ello, la Ley articula medidas que permiten proteger mejor el medio ambiente frente al desarrollo urbano. En concreto, se tienen en cuenta de una manera especial: los cauces fluviales y sus zonas de afectación y la integración de las riberas en los núcleos de población (nuevo art. 36.2 a); la consideración de la contaminación acústica en los planes de ordenación detallada (nuevo art. 36.3); la potenciación de la movilidad sostenible mediante el llamado "urbanismo de proximidad", complementado con la planificación del transporte público (nuevo art. 36 bis); la promoción de la eficiencia energética de edificios y viviendas y el fomento de las energías renovables (nuevo art. 36 ter); la consideración de los riesgos naturales y tecnológicos (nuevo art. 36 quáter); etc. Estamos ante una auténtica ley de "urbanismo sostenible".

\subsection{La ley de reforma de la Administración pública}

La reciente Ley 5/2014, de 11 de septiembre, de medidas para la reforma de la Administración de la Comunidad de Castilla y León, se dirige fundamentalmente a regular aspectos organizativos y procedimentales. Señala la exposición de motivos que "la naturaleza y el contenido de esta ley, si bien se encuadran fundamentalmente en el ejercicio de las competencias exclusivas de autoorganización, involucran, en mayor o menor medida, a un amplio conjunto de competencias autonómicas previstas en el Estatuto de Autonomía”. 
Sin embargo, hay que distinguir claramente entre modificaciones derivadas de la potestad autoorganizativa y modificaciones derivadas de las potestades ad extra (planificadora, sancionadora, etc.) que afectan directamente a la esfera jurídica de los particulares. La normativa sectorial afectada, amplísima, incluye numerosas disposiciones de leyes ambientales o reguladoras de materias relacionadas, en mayor o menor medida, con el medio ambiente.

En cuanto a la potestad autoorganizativa, lo más destacable puede ser la reorganización de los órganos colegiados de asesoramiento y participación en diversos sectores. En el capítulo cuarto, "se racionalizan diversos órganos de asesoramiento y participación existentes con el fin de agilizar y dinamizar su funcionamiento, posibilitando la fusión de varios órganos en uno solo. Para ello, se modifican las referencias expresas a órganos concretos, sustituyéndolas por una referencia genérica a la necesidad de que exista un órgano de asesoramiento y participación en la materia de que se trate" (EM). Quedan afectados por esta reorganización órganos asesores regulados por la Ley 8/1991, de 10 de mayo, de Espacios Naturales, la Ley 4/1996, de 12 de julio, de Caza, la Ley 3/2009, de 6 de abril, de Montes, la recentísima Ley 9/2013, de 3 de diciembre, de Pesca, etc.

Al margen de la reordenación de los órganos colegiados de asesoramiento, la principal novedad ambiental que incluye la Ley es la posibilidad de reducción de las sanciones por pronto pago, siguiendo el modelo de las sanciones de tráfico. Así se deduce del artículo 5 ("Reducción del pago de sanciones pecuniarias").

Las normas ambientales -0 estrechamente relacionadas con el medio ambienteafectadas por esta reforma son las siguientes: Ley 4/1996, de 12 de julio, de Caza de Castilla y León; Ley 5/2009, de 4 de junio, del Ruido de Castilla y León; Ley 11/2003, de 8 abril, de Prevención Ambiental de Castilla y León, cuando se trate de actividades sujetas a autorización ambiental; y Ley 15/2010, de 10 diciembre, de prevención de la contaminación lumínica y del fomento del ahorro y eficiencia energéticos derivados de instalaciones de iluminación.

El objeto de esta reforma — dice la Ley— es la "simplificación administrativa" (el título II en el que se inserta este precepto lleva por epígrafe "Medidas de simplificación"), pero realmente responde a una finalidad recaudatoria. Difícilmente puede hablarse de simplificación administrativa cuando, como señala el citado artículo 5 , el procedimiento sancionador se ha tenido que tramitar en su práctica integridad porque el ejercicio del beneficio derivado del pago voluntario solo se puede ejercer en el plazo de treinta días 
después de la propuesta de resolución. No hay eliminación real de trámites; no hay auténtica simplificación. Lo que se busca es facilitar el pago de sanciones que, hasta el momento, tenían un reducido porcentaje de cumplimiento voluntario.

Estas han sido, pues, las principales reformas de la Administración en el área ambiental, sin perjuicio de la que se señala a continuación, puramente organizativa.

\section{Una pequeña modificación de las comisiones territoriales de Medio Ambiente y Urbanismo}

Decreto 32/2014, de 24 de julio, por el que se modifica el Decreto 24/2013, de 27 de junio, por el que se regulan las funciones, composición y funcionamiento de las Comisiones Territoriales de Medio Ambiente y Urbanismo y del Consejo de Medio Ambiente, Urbanismo y Ordenación del Territorio de Castilla y León.

Estas comisiones cumplen una función esencial en numerosos supuestos de tramitación de procedimientos administrativos de emisión de licencias ambientales y urbanísticas. En este sentido, constituyen el principal órgano colegiado y asesor de la Junta en esta materia con fuerte incidencia en el ámbito local. Como ya se señaló en un comentario de la legislación de 2013, la simplificación administrativa y, en concreto, la tendencia a suprimir órganos innecesarios llevaron a la Administración autonómica a fusionar las comisiones territoriales de Medio Ambiente y las de Urbanismo por el Decreto 24/2013, de 27 de junio. Ahora bien, el funcionamiento de estos nuevos órganos colegiados ha puesto de manifiesto algunas disfuncionalidades en su composición y funciones que el Decreto que se comenta intenta resolver. En concreto, se amplía la representación de las organizaciones sindicales y empresariales y de los colegios profesionales por el alcance amplio de sus competencias. En cuanto a las funciones, se modifica el artículo 163 del Reglamento de Urbanismo aprobado por Decreto 22/2004 para "eliminar las asimetrías subsistentes en el articulado del Reglamento de Urbanismo de Castilla y León, pues lo adecuado es que todos los asuntos de planeamiento urbanístico que afecten a un determinado municipio sean objeto de tratamiento en un mismo órgano colegiado", de forma que se suprime la competencia atribuida en esta materia al Consejo de Medio Ambiente, Urbanismo y Ordenación del Territorio. El alcance de esta modificación, como se ve, es mínimo. 


\section{Un proyecto de interés regional para el tratamiento de residuos industriales}

E1 Decreto 30/2014, de 26 de junio, aprueba el proyecto regional para la instalación de un Centro de Tratamiento Integral de Residuos Industriales no Peligrosos en el entorno formado por las provincias de Burgos y Soria, en el término municipal de Abajas (Burgos).

Se trata, como queda someramente expuesto en el propio texto, de un conjunto de instalaciones de tratamiento y de depósito de residuos industriales no peligrosos. Su finalidad es gestionar correctamente y de modo preferente los residuos de las industrias situadas en el eje Burgos-Soria para minimizar el impacto ambiental. El criterio de tratamiento se ajusta correctamente a la prelación establecida por la propia Ley 22/2011, de 28 de julio, de Residuos y Suelos Contaminados; como señala la propia exposición de motivos, con esta instalación se pretende, en primer lugar, la reutilización de residuos $\mathrm{y}$, subsidiariamente, el reciclaje, la valorización $\mathrm{y}$, por último, y si no cabe otra alternativa, la eliminación mediante depósito en un vertedero controlado.

Claramente, por el objeto y alcance territorial, este grupo de instalaciones cumple los requisitos exigibles a un proyecto regional. Recuérdese - y así lo hace la EM- que los proyectos regionales, según el artículo 20 de la Ley 10/1998, de 5 de diciembre, de Ordenación del Territorio, constituyen "un instrumento de intervención directa en la ordenación del territorio de la Comunidad Autónoma y tienen por objeto planificar y proyectar la ejecución inmediata de las infraestructuras de utilidad pública o interés social, que se consideren de interés para la Comunidad".

Por otro lado, es de agradecer que, desde el punto de vista formal-procedimental, la Junta haya optado por utilizar el instrumento adecuado: un decreto de aprobación del proyecto y no una ley. El castigo que el Constitucional ha infligido a las leyes de convalidación de proyectos de interés regional ha facilitado que las aguas vuelvan a su cauce: mediante un decreto se aseguran, paradójicamente, las garantías de participación y control judicial que la ley bloquea.

\section{Una ley que deja de serlo: la inconstitucionalidad de la Ley de convalidación del proyecto Meseta-Sky}

Acabamos de aludir al castigo del Tribunal Constitucional a las leyes de convalidación de Castilla y León en materia ambiental. El último ejemplo lo constituye la reciente 
Sentencia del Alto Tribunal de 7 de octubre, que declara contraria a la Carta Máxima la Ley 6/2010, de 28 de mayo, de declaración de Proyecto Regional del "Complejo de Ocio y Aventura Meseta-Ski”.

Sin entrar en grandes profundidades, porque ya se ha aludido a este conflicto en comentarios anteriores, baste recordar que las Cortes regionales, con un sorprendente consenso, aprobaron en 2010 la ley singular de este peculiar proyecto de instalaciones de "esquí seco" en las proximidades de Tordesillas (Valladolid), proyecto propuesto por la Diputación vallisoletana y que se intentó llevar a cabo en unos terrenos parte de los cuales constituían suelo rústico de uso forestal y habían sido objeto de un incendio no intencionado unos años antes. Es sabido que la Ley estatal de Montes prohíbe el cambio de uso forestal de los terrenos incendiados durante, al menos, treinta años (artículo 50.1 de la Ley 43/2003, de 21 de noviembre, de Montes), por lo que — al menos parcial y formalmente - la Ley regional estaba contraviniendo la normativa básica estatal. E1 Tribunal Constitucional no entra en su resolución en otros aspectos (tutela judicial efectiva, proporcionalidad del uso de la ley singular) como había hecho al analizar las leyes de convalidación del centro de transferencia de Santovenia y del proyecto urbanístico de la Ciudad del Medio Ambiente. Le basta contrastar la norma básica y la regional para reconocer la inconstitucionalidad indirecta de esta por infracción de aquella. Estamos ante una tercera sentencia de anulación de leyes de convalidación en poco más de un año, lo que supone un enorme varapalo para la política ambiental de la Junta. El procedimiento administrativo permite la participación y la tutela judicial de los afectados, y estas garantías, especialmente trascendentes en materia ambiental, se han visto reducidas o eliminadas por las leyes de convalidación que ahora están siendo anuladas por el Tribunal Constitucional. 